\title{
Integrating The Boost: Development Of A Hybrid Volumetric Modulated Arc Based Simultaneous Integrated Boost Class Solution For Breast Cancer
}

\section{Sanjoy Chatterjee}

Tata Medical Center, Kolkata

Anurupa Mahata

Tata Medical Center, Kolkata

Samar Mandal

Tata Medical Center, Kolkata

Santam Chakraborty ( $\nabla$ drsantam@gmail.com )

Tata Medical Center

\section{Research Article}

Keywords: Breast Cancer, Tumor Bed Boost, Simultaneous Integrated Boost, Volumetric Modulated Arc Radiotherapy

Posted Date: July 2nd, 2021

DOl: https://doi.org/10.21203/rs.3.rs-677563/v1

License: (9) This work is licensed under a Creative Commons Attribution 4.0 International License. Read Full License 


\section{Abstract \\ Purpose:}

We describe the development of a simultaneous integrated boost (SIB) class solution employing a hybrid Volumetric Modulated Arc Therapy (VMAT) for adjuvant treatment of breast cancer where conformal avoidance of normal organs from low dose is prioritized.

\section{Methods:}

A field in field tangent pair was used to irradiate the whole breast while the VMAT SIB was used to deliver a boost to the tumor bed with a margin of $5 \mathrm{~mm}$. Hybrid VMAT SIB was planned in 25 patients using two short arcs of 30 degrees each offset by 5-10 degrees from the medial and lateral tangent angles respectively. SIB dose of $8 \mathrm{~Gy}$ was prescribed in addition to the whole breast dose of $40 \mathrm{~Gy}$ in 15 fractions. Plans were compared against a standard sequential mini-tangent boost plan (SEQ) delivering a dose of $12 \mathrm{~Gy}$ in 4 fractions using the Wilcoxon Signed-Rank test. Mean probability of developing grade 2 or more fibrosis was estimated using the NTCP formula provided by Hammer et al.

\section{Results:}

VMAT SIB significantly improved conformity as compared to the SEQ plan $(0.51$ vs $0.35, p<0.01)$. Target volume coverage was similar between the two techniques. The mean dose to the contralateral breast, contralateral lung, and heart was increased by $0.13 \mathrm{~Gy}, 0.02 \mathrm{~Gy}$, and $0.03 \mathrm{~Gy}$ respectively which was clinically insignificant. The mean probability of developing Grade 2 fibrosis at 5 years was similar between the two techniques $(2.5 \%$ vs $2.7 \% \mathrm{p}=0.19)$. The class solution achieved consistent plans across a wide range of sites and target volume ranges $\left(35.38-247.10 \mathrm{~cm}^{3}\right)$. The average total MU requirement was significantly reduced (593 vs $848.6, \mathrm{p}<0.01)$.

\section{Conclusion:}

A class solution for VMAT SIB was developed which satisfied the planning objectives. This solution will be used for a prospective randomized trial investigating a one-week hypofractionated schedule of radiotherapy.

\section{Introduction}

A boost to the tumor bed improves the local control after breast conservation therapy (BCS) but increases the treatment duration [1]. Integrating the boost with whole-breast irradiation (WBI) can reduce this duration. This simultaneous integrated boost (SIB) when planned using traditional 3DCRT exposes larger volumes of the breast to a higher dose per fraction [2]. This may increase the risk of consequential 
fibrosis which could thereby translate into poorer cosmesis [3-7]. At the same time using IMRT for planning for WBI increases the low dose exposure to the opposite breast, lung, and heart.

We present a class solution for planning a hybrid volumetric modulated arc therapy (VMAT) to deliver SIB and compare the dosimetric results to a conventional technique employing a mini-tangent sequential boost (SEQ).

\section{Methods \& Materials}

\section{Population}

Planning CT scans of 25 consecutive patients post BCS was used to plan the SIB class solution. We use a field-based planning technique for WBI and supraclavicular irradiation (SCF). For each patient, the anatomical boundaries for tangential breast irradiation were delineated as described in our previous report [8]. The tumor bed was delineated around the clips placed at the time of surgery along with the visualized postoperative abnormalities and $5 \mathrm{~mm}$ isotropic expansion was given to obtain the boost planning target volume (BTV). As a retrospective dosimetric planning study using patients' previously obtained planning CT the study was exempt from review by the institute IRB.

\section{Radiotherapy Planning}

A dose of $40 \mathrm{~Gy}$ in 15 fractions (2.67 Gy) was prescribed to the WBI ( $\triangle \mathrm{SCF}$ ), while the BTV received 0.53 Gy additionally per fraction (total dose $=48 \mathrm{~Gy}$ in 15 fractions). For the SEQ plans, the same WBI dose was followed by a boost of $12 \mathrm{~Gy}$ in 4 fractions to the tumor bed planned using mini-tangents. The duration of planned treatment was 3 weeks for SIB and 4 weeks for SEQ plans. All plans were generated using the Eclipse treatment planning system version 15.1 (Varian Medical System, Palo Alto, USA)

Casebow's technique of couch and collimator rotation was utilized to ensure a non-divergent match plane between the tangents and SCF fields as well as the posterior edge of the two tangents [9]. This technique provides a generalized solution for calculating the gantry, collimator and couch rotation based on the length and inclination of the target (Appendix 1). The tangential fields and the VMAT fields shared the same isocenter.

SIB VMAT was planned using two coplanar arcs without couch rotation. The arc start angles were chosen with a $5-10$ degree medial offset from respective tangents (Appendix 1). Arc lengths of $30-35$ degrees were utilized for both arcs. Initial VMAT optimization was done using the following constraints using the Progressive Resolution Optimizer version 15.1.1. Typically 3 - 4 plan iterations were required to obtain a good quality plan.

Plan quality assurance was performed using point dosimetry for absolute dose verification with a 0.053 cc Farmer's chamber inside a cheese phantom. Relative dose verification for the VMAT SIB plan was done 
using portal dosimetry. Pass criteria were dose tolerance $3 \%$ of the reference dose for absolute dosimetry, and area gamma of $97 \%$ for an average dose difference of $3 \%$ to $3 \mathrm{~mm}$.

\section{Dosimetric Comparisons}

The summed doses of the SIB plan were compared against the summed doses of the approved SEQ plans used for treatment. Paired means of doses to different organs were compared using the Wilcoxon Signed-Rank test.

The formulae used for computation of the conformity and homogeneity indices are:

\section{Conformity Index =}

\section{Conformity Index}

$$
=\frac{B T V(c c)}{\text { Volume of breast receiving } 95 \% \text { of the prescribed dose } *}
$$

*For SIB Plans: 95\% of the prescribed dose (48 Gy) was 4560 cGy

*For Seq Plans: $95 \%$ of the prescribed dose (52 Gy) was 4940 cGy

\section{Homogeneity Index}

Homogenity Index

$$
=\frac{(\text { Minimum dose to } 2 \% \text { of BTV }- \text { Minimum dose to } 98 \% \text { of BTV })}{\text { Median Dose to BTV }}
$$

BTV $=$ Boost Target Volume

As the use of SIB increases the dose per fraction and when used with hypofractionated schedules may increase the probability of breast fibrosis due to the so-called triple trouble [10], we estimated the probability for grade 2 or more radiation-induced fibrosis using a predictive equation developed by Hammer et al. This model requires age, the percentage volume of breast CTV receiving $\geq 55$ Gy (EQD2 = $52.3 \mathrm{~Gy}_{3}$ ) and the maximum dose as variables [5]. The EQD2 $52.3 \mathrm{~Gy}$ corresponded to the physical dose of $44.1 \mathrm{~Gy}$ for the SIB schedule and $47.5 \mathrm{~Gy}$ for the SEQ schedule. The $50 \%$ isodose of the tangential plan ( $40 \mathrm{~Gy}$ total dose) subtracted from the lung was used as the breast CTV. The volume of this CTV receiving 44.1 Gy (SIB) or 47.5 Gy (SEQ) was estimated. The plan Dmax was converted into EQD2 for a balanced comparison between plans. The predictive equation as given by Hammer et al is: 
$N T C P=\left(1+e^{-s}\right)^{-1}$

where, $S=-19.386+(0.218 \times$ Dmax $)+(0.026 \times$ V55*) $+(0.025 \times$ Age $)$

\section{Results}

Of the patients, $13(52 \%)$ had left-sided breast cancer, SCF radiation was used in 17 (68\%) patients. The average age of the patients was 48.8 years ( $95 \% \mathrm{Cl}$ : $43.9-53.0$ years). The location of the tumors is depicted in Figure 1 for these patients. The mean BTV was $107.0 \mathrm{~cm}^{3}$ (range: $35.38-247.10 \mathrm{~cm}^{3}$ ).

The average total monitor units required for SIB was 593.0 (95\% confidence intervals : 537.7 - 648.3) as compared to $848.6(95 \% \mathrm{Cl}: 794.6$ - 902.5) for SEQ $(p<0.01)$. SIB improved the conformity while maintaining the coverage and dose homogeneity. The mean probability of developing Grade 2 or more fibrosis in the breast at 5 years was $2.5 \%(95 \% \mathrm{Cl}: 1.9 \%-3.1 \%)$ in the SIB plans versus $2.7 \%$ (95\% Cl: $2.3 \%$ $-3.2 \%)$ in the SEQ plans $(p=0.19)$. Table 1 presents the dosimetric comparison between the two techniques for different volumes.

\section{Discussion}

Several studies have now reported SIB for breast cancer. A review of the literature identified 10 prospective trials investigating this strategy, of which 6 have reported medium to long-term results (Table 2) [11-16]. Additionally, the results of the IMPORT-High trials presented recently suggest that SIB can be delivered without excess toxicities when the total dose is reduced appropriately [17]. However, most of the reports employing VMAT have treated the entire breast and tumor bed together $[11,13,15]$.

Our technique of hybrid VMAT SIB emphasizes conformal avoidance of the contralateral breast, lung, and heart with the use of small arc lengths and use of tangents. This improves conformal avoidance for low dose, as compared to the treatment of the entire volume with VMAT. At the same time, the dose conformity is improved. Our SIB treatment planning approach is similar in principle to the one used in the IMPORT High trial [17]. The small increase in mean dose to the opposite breast is unlikely to translate into any clinically appreciable increased risk of second breast cancer [18].

The use of VMAT for SIB allows faster treatment delivery (arc delivery time range: 0.33 - 0.42 minutes) which allows it to be combined with voluntary breath-hold techniques without requiring interruption of the arc. The class solution developed allows the planner to quickly select the starting arc geometries in combination with the tangential fields. With practice, treatment planning can now be completed in 6 - 7 hours.

\section{Conclusions}

Our hybrid VMAT class solution allows enables the adoption of SIB in a busy clinical setting. In addition to the similar risk of breast fibrosis, the low dose exposure to other thoracic organs is also minimized, 
whilst improving the conformity in the target volume. The proposed class solution will be utilized in a randomized controlled trial investigating a shorter course of hypofractionated radiotherapy in breast cancer (HYPORT Adjuvant)[19].

\section{References}

1. Bartelink H, Maingon P, Poortmans $P$, Weltens $C$, Fourquet A, Jager $J$, et al. Whole-breast irradiation with or without a boost for patients treated with breast-conserving surgery for early breast cancer: 20-year follow-up of a randomised phase 3 trial. Lancet Oncol [Internet]. 2015 Jan 1;16(1):47-56. Available from: http://www.sciencedirect.com/science/article/pii/S1470204514711568

2. Horton JK, Halle JS, Chang SX, Sartor Cl. Comparison of three concomitant boost techniques for early-stage breast cancer. Int J Radiat Oncol Biol Phys [Internet]. 2006 Jan 1;64(1):168-75. Available from: http://dx.doi.org/10.1016/j.jijobp.2005.07.004

3. Mukesh MB, Barnett GC, Wilkinson JS, Moody AM, Wilson C, Dorling L, et al. Randomized controlled trial of intensity-modulated radiotherapy for early breast cancer: 5-year results confirm superior overall cosmesis. J Clin Oncol [Internet]. 2013 Dec 20;31(36):4488-95. Available from: http://dx.doi.org/10.1200/JC0.2013.49.7842

4. Mak KS, Chen Y-H, Catalano PJ, Punglia RS, Wong JS, Truong L, et al. Dosimetric Inhomogeneity Predicts for Long-Term Breast Pain After Breast-Conserving Therapy. Int J Radiat Oncol Biol Phys [Internet]. 2015 Dec 1;93(5):1087-95. Available from: http://dx.doi.org/10.1016/j.ijrobp.2014.05.021

5. Hammer C, Maduro JH, Bantema-Joppe EJ, van der Schaaf A, van der Laan HP, Langendijk JA, et al. Radiation-induced fibrosis in the boost area after three-dimensional conformal radiotherapy with a simultaneous integrated boost technique for early-stage breast cancer: A multivariable prediction model. Radiother Oncol [Internet]. 2017 Jan;122(1):45-9. Available from: http://dx.doi.org/10.1016/j.radonc.2016.10.006

6. Brouwers PJAM, van Werkhoven E, Bartelink H, Fourquet A, Lemanski C, van Loon J, et al. Predictors for poor cosmetic outcome in patients with early stage breast cancer treated with breast conserving therapy: Results of the Young boost trial. Radiother Oncol [Internet]. 2018 Sep;128(3):434-41. Available from: http://dx.doi.org/10.1016/j.radonc.2018.06.020

7. Kindts I, Defraene G, Laenen A, Petillion S, Van Limbergen E, Depuydt T, et al. Development of a normal tissue complication probability model for late unfavourable aesthetic outcome after breastconserving therapy. Acta Oncol [Internet]. 2018 Jul;57(7):916-23. Available from: http://dx.doi.org/10.1080/0284186X.2018.1461926

8. Nandi M, Mahata A, Mallick I, Achari R, Chatterjee S. Hypofractionated radiotherapy for breast cancers--preliminary results from a tertiary care center in eastern India. Asian Pac J Cancer Prev [Internet]. 2014;15(6):2505-10. Available from: http://www.ncbi.nlm.nih.gov/pubmed/24761855 
9. Casebow MP. Angulation of radiotherapy treatment machines in a non-co-planar field technique. $\mathrm{Br} \mathrm{J}$ Radiol [Internet]. 1980 Mar;53(627):259-60. Available from: http://dx.doi.org/10.1259/0007-1285-53627-259

10. Yarnold J, Bentzen SM, Coles C, Haviland J. Hypofractionated whole-breast radiotherapy for women with early breast cancer: myths and realities. Int J Radiat Oncol Biol Phys [Internet]. 2011 Jan 1;79(1):19. Available from: http://dx.doi.org/10.1016/j.jijrobp.2010.08.035

11. Franco P, Zeverino M, Migliaccio F, Cante D, Sciacero P, Casanova Borca V, et al. Intensity-modulated and hypofractionated simultaneous integrated boost adjuvant breast radiation employing statics ports of tomotherapy (TomoDirect): a prospective phase II trial. J Cancer Res Clin Oncol [Internet]. 2014 Jan;140(1):167-77. Available from: http://dx.doi.org/10.1007/s00432-013-1560-8

12. Cooper BT, Formenti-Ujlaki GF, Li X, Shin SM, Fenton-Kerimian M, Guth A, et al. Prospective Randomized Trial of Prone Accelerated Intensity Modulated Breast Radiation Therapy With a Daily Versus Weekly Boost to the Tumor Bed [Internet]. Vol. 95, International journal of radiation oncology, biology, physics. 2016. p. 571-8. Available from: https://www.ncbi.nlm.nih.gov/pubmed/27131077

13. De Rose F, Fogliata A, Franceschini D, Navarria P, Villa E, Iftode C, et al. Phase II trial of hypofractionated VMAT-based treatment for early stage breast cancer: 2-year toxicity and clinical results. Radiat Oncol [Internet]. 2016 Sep 17;11(1):120. Available from: http://dx.doi.org/10.1186/s13014-0160701-z

14. Shin SM, No HS, Vega RM, Fenton-Kerimian M, Maisonet O, Hitchen C, et al. Breast, chest wall, and nodal irradiation with prone set-up: Results of a hypofractionated trial with a median follow-up of 35 months. Pract Radiat Oncol [Internet]. 2016 Jul;6(4):e81-8. Available from: http://dx.doi.org/10.1016/j.prro.2015.10.022

15. Mondal D, Julka PK, Sharma DN, Jana M, Laviraj MA, Deo SV, et al. Accelerated hypofractionated adjuvant whole breast radiation with simultaneous integrated boost using volumetric modulated arc therapy for early breast cancer: A phase I/II dosimetric and clinical feasibility study from a tertiary cancer care centre of India. J Egypt Natl Canc Inst [Internet]. 2017 Mar;29(1):39-45. Available from: http://dx.doi.org/10.1016/j.jnci.2017.01.005

16. Cante D, Petrucci E, Sciacero P, Piva C, Ferrario S, Bagnera S, et al. Ten-year results of accelerated hypofractionated adjuvant whole-breast radiation with concomitant boost to the lumpectomy cavity after conserving surgery for early breast cancer. Med Oncol [Internet]. 2017 Sep;34(9):152. Available from: http://dx.doi.org/10.1007/s12032-017-1020-4

17. Coles CE, Griffin CL, Kirby AM, Haviland JS, Titley JC, Benstead K, et al. Dose escalated simultaneous integrated boost radiotherapy for women treated by breast conservation surgery for early breast cancer: 3-year adverse effects in the IMPORT HIGH trial (CRUK/06/003) [Internet]. San Antonio Breast Cancer 
Symposium; 2018 Dec 6 [cited 2018 Nov 30]; San Antionio, Texas, USA. Available from: https://www.abstracts2view.com/sabcs18/view.php?nu=SABCS18L_527\&terms=

18. Stovall M, Smith SA, Langholz BM, Boice JD Jr, Shore RE, Andersson M, et al. Dose to the contralateral breast from radiotherapy and risk of second primary breast cancer in the WECARE study. Int J Radiat Oncol Biol Phys [Internet]. 2008 Nov 15;72(4):1021-30. Available from: http://dx.doi.org/10.1016/j.jijrobp.2008.02.040

19. Chatterjee S, Chakraborty S, HYPORT Adjuvant Author Group. Hypofractionated radiation therapy comparing a standard radiotherapy schedule (over 3 weeks) with a novel 1-week schedule in adjuvant breast cancer: an open-label randomized controlled study (HYPORT-Adjuvant)-study protocol for a multicentre, randomized phase III trial. Trials [Internet]. 2020 Sep 30;21(1):819. Available from: http://dx.doi.org/10.1186/s13063-020-04751-y

\section{Tables}

Table 1: Showing the comparison between SIB and SEQ plans for various volumes. Figures represent the mean and 95\% confidence intervals. $P$ values are derived from wilcoxon signedrank test and values less than 0.05 considered as statistically significant. D98 = Dose to $98 \%$ volume, D2 = Dose to $2 \%$ Volume, V95= Percentage volume receiving 95\% prescribed dose, V0.5 = Percentage volume receiving $0.5 \mathrm{~Gy}$ dose, Dmean $=$ Mean dose to volume, V12= Percentage Volume receiving 12 Gy. BTV = Boost Target Volume 


\begin{tabular}{|c|c|c|c|c|}
\hline Volume & $\begin{array}{l}\text { Dosimetric } \\
\text { Parameter }\end{array}$ & SIB Technique & SEQ Technique & $\begin{array}{l}\mathrm{p}- \\
\text { value }\end{array}$ \\
\hline \multirow[t]{5}{*}{ BTV } & D98 (\%) & $95.5(94.7-96.4)$ & $94.9(94.0-95.9)$ & 0.38 \\
\hline & D2 (\%) & $\begin{array}{l}103.2(102.5- \\
103.9)\end{array}$ & $\begin{array}{l}102.9(102.0- \\
103.8)\end{array}$ & 0.85 \\
\hline & Conformity Index & $0.52(0.47-0.56)$ & $0.31(0.28-0.35)$ & $<0.01 *$ \\
\hline & Homogeneity Index & $0.08(0.07-0.08)$ & $0.08(0.07-0.09)$ & 0.44 \\
\hline & V95 (\%) & $97.9(96.9-98.9)$ & 97.7 (97.0 - 98.7) & 0.88 \\
\hline \multirow{2}{*}{$\begin{array}{l}\text { Contralateral } \\
\text { Breast }\end{array}$} & Dmean (Gy) & $0.25(0.17-0.32)$ & $0.12(0.10-0.15)$ & $<0.01^{*}$ \\
\hline & V0.5 (\%) & $14.1(10.5-17.8)$ & $7.7(5.8-9.6)$ & $\begin{array}{l}< \\
0.01 *\end{array}$ \\
\hline \multirow[t]{2}{*}{$\begin{array}{l}\text { Contralateral } \\
\text { Lung }\end{array}$} & Dmean (Gy) & $0.16(0.13-0.19)$ & $0.14(0.12-0.17)$ & $\begin{array}{l}< \\
0.01 *\end{array}$ \\
\hline & V0.5 (\%) & $4.9(3.4-6.4)$ & $3.4(2.0-4.8)$ & $\begin{array}{l}< \\
0.01 *\end{array}$ \\
\hline \multirow[t]{2}{*}{ Heart } & Dmean (Gy) & $0.90(0.73-1.07)$ & $0.87(0.69-1.04)$ & $0.01 *$ \\
\hline & V0.5 (\%) & $56.5(48.8-64.1)$ & $53.5(43.6-63.4)$ & $0.03 *$ \\
\hline \multirow[t]{2}{*}{ Ipsilateral Lung } & V12 (\%) & $15.8(13.1-18.4)$ & $15.6(12.9-18.4)$ & 0.12 \\
\hline & Dmean (Gy) & $6.64(5.80-7.49)$ & $6.66(5.79-7.54)$ & 0.81 \\
\hline
\end{tabular}

Table 2: Showing the treatment techniques and outcomes of studies investigating simultaneous integrated boost. Studies which have reported medium to long-term outcomes are only included.

\begin{tabular}{|c|c|c|c|c|c|}
\hline Author (Year) & $\mathbf{N}$ & Technique & FU & $\begin{array}{l}\text { Local } \\
\text { Control }\end{array}$ & $\begin{array}{l}\text { Good } \\
\text { Cosmesis }\end{array}$ \\
\hline $\begin{array}{l}\text { Franco }(2014) \\
{[11]}\end{array}$ & 82 & $\begin{array}{l}\text { Tomotherapy (Whole Breast + } \\
\text { Boost) }\end{array}$ & 12 & $100 \%$ & $91 \%$ \\
\hline $\begin{array}{l}\text { Cooper (2016) } \\
{[12]}\end{array}$ & 400 & Prone Tangential + IMRT Boost & 45 & $99 \%$ & $80 \%$ \\
\hline $\begin{array}{l}\text { De Rose (2016) } \\
\text { [13] }\end{array}$ & 144 & $\begin{array}{l}\text { VMAT (Whole Breast + Tumor } \\
\text { Bed) }\end{array}$ & 37 & $100 \%$ & NA \\
\hline Shin (2016) [14] & 45 & Prone 3 Field IMRT & 36 & $100 \%$ & $85 \%$ \\
\hline $\begin{array}{l}\text { Mondal (2017) } \\
{[15]}\end{array}$ & 10 & $\begin{array}{l}\text { VMAT (Whole Breast + Tumor } \\
\text { Bed) }\end{array}$ & 24 & $100 \%$ & $100 \%$ \\
\hline Cante (2017) [16] & 178 & Tangential + Direct Photon Boost & 117 & $97.3 \%$ & $87.80 \%$ \\
\hline
\end{tabular}




\section{Declarations}

\section{Conflicts of Interest}

The authors declare no conflicts of interest

\section{Figures}

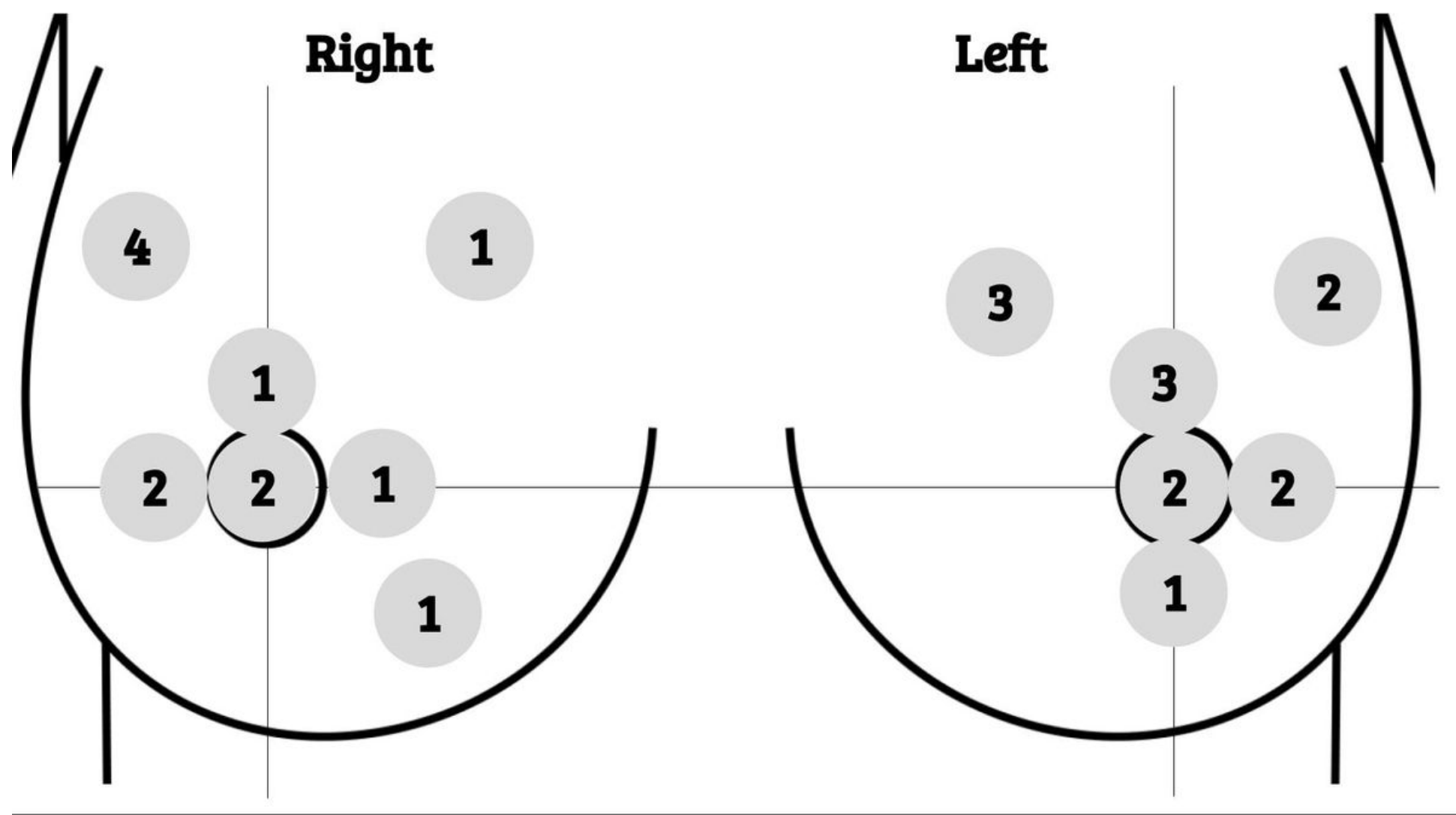

Figure 1

Showing the locations of the tumor beds in the 25 patients included in the study.

\section{Supplementary Files}

This is a list of supplementary files associated with this preprint. Click to download.

- AppendixABreastSIBIMRTCommissioningPaper2.pdf 